\title{
Blood flow to the femoral head during different surgical approaches to the hip: a systematic review of literature
}

\author{
H. Amarasekera \\ Department of Orthopaedics, University of Warwick, School of Medicine, United Kingdom
}

Key words: Posterior approach; blood flow; avascular necrosis; hip resurfacing, systematic review; randomised control trial

\begin{abstract}
A systematic review was conducted to answer the question, "Does the surgical approach influence the blood flow to the femoral head?".

All articles published from January 1990 to September 2014 were included. Multiple databases were used for the search. Search criteria revealed 19 articles initially and 11 articles for the final analysis (Figure 1). These were further analysed using a data extraction form (Figure 2). Each article was critically appraised. No randomised control trial (RCT) was found in the search and the remaining studies did not clearly show a significant reduction in blood flow during a posterior approach that can be directly linked to the development of avascular necrosis.
\end{abstract}

\section{Introduction}

The blood supply to the femoral head and its' clinical implications has been a debatable topic among anatomists, surgeons and orthopaedic surgeons for many years. The macroscopic anatomy of the arterial supply and the venous drainage of the femoral head have been studied since the late 1940s [1]. However, the clinical effects and functional outcome following disruption to the blood supply of the femoral head is less understood. At present there appears to be a general consensus that the blood flow to the femoral head is reduced during an acute disruption to the main vessels. This acute disruption of the blood supply can be caused by fractures of the femoral head, posterior dislocation of the hip joint or by surgery.

However the immediate and long-term clinical effects this has on the femoral head is less clearly understood. Most studies also fail to distinguish between surgeries and fractures. A systematic review of literature was conducted to answer the question, "Does the surgical approach influence the blood flow to the femoral head?".

Correspondence: H. Amarasekera

E-mail: hiruwan@googlemail.com

DOI: http://10.4038/sljs.v34i2.8263

\section{(cc) BY}

The Sri Lanka Journal of Surgery 2016; 34(2): 18-22

\section{Materials and methods}

The objective of the study was to find out the blood flow to the femoral head during different surgical approaches. An Internet based search was done to obtain the data. A detailed systematic review was conducted using search engines Google Scholar, TRIP Database (www.tripdatabase.com) and NHS evidence (www.evidence.nhs.uk). The inclusion and exclusion criteria are given below.

\section{Inclusion criteria}

1. All articles published from January 1990 till September 2014

2. Articles published in the english language or translated to the english language

3. Articles that were indexed in Pubmed Medline and CINAHL (Cumulative Index to Nursing and Allied health) databases

\section{Exclusion Criteria}

1. All articles that were not in the english language nor translated to english

2. Articles that were published before 1990

3. Studies not involving humans (animal studies)

4. Irrelevant articles. Any articles that were retrieved by the database search, but were irrelevant to the research question were manually excluded after reviewing the abstracts

5. Duplicate articles. If multiple searches from the three search engines Pubmed, EMBASE and CINAHL reveal duplicate articles, these were removed manually

\section{The Search Strategy}

The following search strategy was carried using the Medline/Pubmed database with the search period from January 1990 to September 2014.

The combined databases of EMBASE and CINHAL retrieved 9 articles [5-8,12-16]. The final combination of PubMed, EMBASE and CINAHL search retrieved 19 articles in total. After the duplicates were removed 15 articles were retrieved for the final analysis. The abstract of all fifteen articles were initially reviewed. Articles irrelevant to the research question that had been retrieved by the system had to be manually excluded. There were 4 such articles that were removed $[10,13,14,16]$. Finally 11 articles were identified for analysis [2-9,11,12,15] (Figure 1). 


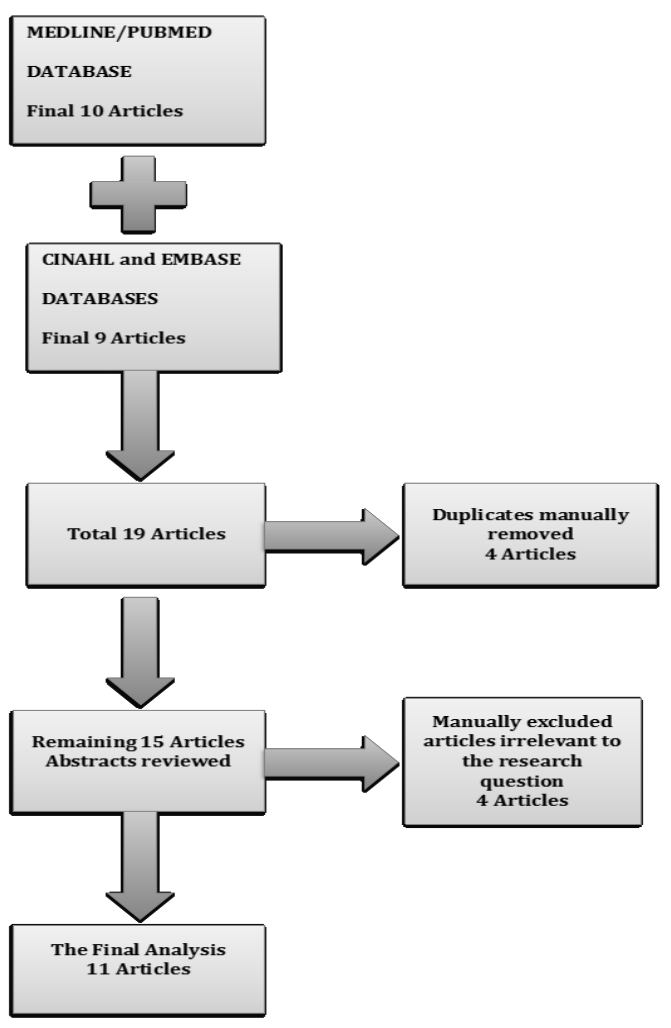

Figure 1. Search protocol.

\section{Results}

The final 11 articles are given in Table 1.

\section{Discussion}

The final 11 articles were critically appraised individually.

In the article Titled "The effect of surgical approach on blood flow the femoral head during hip resurfacing", Khan et al [7] reported on 20 patients, 9 undergoing the procedure through a trans-gluteal approach and 11 through an extended posterior approach. Blood flow was measured using cefuroxime concentration in bone samples as a surrogate to blood flow to the femoral head. They found the posterior approach to show a significant drop in blood flow as compared to the trans-gluteal approach. The paper does not include a sample size calculation. Secondly cefuroxime concentration in tissues will depend on many pharmacokinetic and pharmacodynamic factors. There is no evidence that the authors have accounted for this error in this paper. Authors mention that one patient did not have any traces of the drug while another had a high level. Authors do not mention the exact site where the measurement was taken therefore it may or may not be uniformly distributed among all patients. Thirdly the study is not randomised and

\begin{tabular}{|c|c|c|c|c|c|c|}
\hline Article No & $\begin{array}{l}\text { Journal } \\
\text { \& Impact } \\
\text { factor } \\
(2012)\end{array}$ & Study Design & Patients & Intervention & Comparison & $\begin{array}{l}\text { Outcome } \\
\text { Primary } \\
\text { Secondary }\end{array}$ \\
\hline $1{\mathrm{Khan} \mathrm{et} a l^{7}}^{2}$ & $\begin{array}{l}\text { JBJS Br } \\
(2.83)\end{array}$ & $\begin{array}{l}\text { Prospective } \\
\text { Non } \\
\text { randomised }\end{array}$ & $\begin{array}{l}9 \text { trans- } \\
\text { gluteal }\end{array}$ & $\begin{array}{l}\text { Femoral head } \\
\text { bone sample } \\
\text { cefuroxime } \\
\text { levels }\end{array}$ & $\begin{array}{l}11 \text { Postero- } \\
\text { lateral }\end{array}$ & $\begin{array}{l}\text { Cefuroxime } \\
\text { concentration }\end{array}$ \\
\hline $\begin{array}{l}2 \text { Steffen et } \\
a l^{9}\end{array}$ & $\begin{array}{l}\text { JBJS Br } \\
(2.83)\end{array}$ & $\begin{array}{l}\text { Prospective } \\
\text { Non } \\
\text { randomised }\end{array}$ & $\begin{array}{l}10 \\
\text { Posterior }\end{array}$ & $\begin{array}{l}\text { Femoral neck } \\
\text { blood sample }\end{array}$ & None & $\begin{array}{l}\text { Femoral neck Oxygen } \\
\text { concentration } \\
\text { At different stages }\end{array}$ \\
\hline 3 Khan et al ${ }^{2}$ & $\begin{array}{l}\text { Hip } \\
\text { International } \\
(0.76)\end{array}$ & $\begin{array}{l}\text { Prospective } \\
\text { Non } \\
\text { randomised }\end{array}$ & 46 & $\begin{array}{l}\text { Trochanteric } \\
\text { flip }\end{array}$ & Anterolateral & $\begin{array}{l}\text { Harris and Oxford scores } \\
\mathrm{X} \text { rays }\end{array}$ \\
\hline $\begin{array}{l}4 \text { Schoeniger } \\
\text { et al }\end{array}$ & $\begin{array}{l}\text { CORR } \\
(2.53)\end{array}$ & $\begin{array}{l}\text { Prospective } \\
\text { Non } \\
\text { randomised }\end{array}$ & $\begin{array}{l}10 \text { trans- } \\
\text { gluteal } \\
\text { epiphyseal }\end{array}$ & $\begin{array}{l}\text { LASER } \\
\text { Doppler }\end{array}$ & $\begin{array}{l}\text { Metaphyseal } \\
\text { blood flow }\end{array}$ & $\begin{array}{l}\text { Blood flow in Flux at } \\
\text { different stages }\end{array}$ \\
\hline${ }_{4}^{5}$ Steffen et al & CORR (2.53) & $\begin{array}{l}\text { Prospective } \\
\text { Non } \\
\text { randomised }\end{array}$ & $\begin{array}{l}15 \\
\text { Trochanteric } \\
\text { flip }\end{array}$ & $\begin{array}{l}\text { Femoral head } \\
\text { electrode }\end{array}$ & Previous data & $\begin{array}{l}\text { Femora head oxygen } \\
\text { concentration }\end{array}$ \\
\hline $\begin{array}{l}6 \\
\text { Amarasekera } \\
\text { et al }\end{array}$ & $\begin{array}{l}\text { JBJS Br } \\
(2.83)\end{array}$ & $\begin{array}{l}\text { Prospective } \\
\text { Non } \\
\text { randomised }\end{array}$ & $\begin{array}{l}12 \\
\text { Trochanteric } \\
\text { flip }\end{array}$ & $\begin{array}{l}\text { Femoral head- } \\
\text { neck LASER } \\
\text { Doppler }\end{array}$ & 12 Posterior & Femoral head-neck Flux \\
\hline${ }_{6}^{7}$ Steffen et al & $\begin{array}{l}\text { JBJS Br } \\
(2.83)\end{array}$ & $\begin{array}{l}\text { Prospective } \\
\text { non } \\
\text { randomised }\end{array}$ & $\begin{array}{l}12 \text { Antero- } \\
\text { lateral } \\
\text { approach }\end{array}$ & $\begin{array}{l}\text { Femoral head } \\
\text { electrode }\end{array}$ & $\begin{array}{l}\text { Previous } \\
\text { published } \\
\text { posterior }\end{array}$ & $\begin{array}{l}\text { Femoral head oxygen } \\
\text { concentration }\end{array}$ \\
\hline${ }_{8}^{8 \text { Beaule et al }}$ & CORR (2.53) & Descriptive & $\begin{array}{l}10 \text { Vascular } \\
\text { preserving }\end{array}$ & $\begin{array}{l}\text { Femoral head } \\
\text { Laser Doppler }\end{array}$ & None & Femoral head Flux level \\
\hline $\begin{array}{l}9 \text { Sugamoto et } \\
\text { al }{ }^{11}\end{array}$ & CORR (2.53) & Case series & $\begin{array}{l}44 \text { (28- NOF, } \\
16 \text { IT) }\end{array}$ & $\begin{array}{l}\text { Femoral head } \\
\text { Laser Doppler }\end{array}$ & $\begin{array}{l}14 \mathrm{OA} \\
\text { Patients }\end{array}$ & Femoral head`flux \\
\hline $\begin{array}{l}10 \text { Steffen et } \\
\text { al }{ }^{12}\end{array}$ & $\begin{array}{l}\text { JBJS Br } \\
(2.53)\end{array}$ & Retrieval study & $\begin{array}{l}19 \text { specimens } \\
\text { NOF }\end{array}$ & Histology & $\begin{array}{l}16 \text { specimens } \\
\text { other reasons }\end{array}$ & $\begin{array}{l}\text { Empty lacunae counts to } \\
\text { measure AVN }\end{array}$ \\
\hline $\begin{array}{l}11 \text { Beaule et } \\
\text { al }^{15}\end{array}$ & $\begin{array}{l}\text { JBJS A } \\
(3.27)\end{array}$ & $\begin{array}{l}\text { Cadaveric } \\
\text { study }\end{array}$ & $\begin{array}{l}174 \\
\text { cadaveric hip } \\
\text { specimens }\end{array}$ & Dissections & None & $\begin{array}{l}\text { Mapping of vascular } \\
\text { anatomy }\end{array}$ \\
\hline
\end{tabular}

Table 1. Summary of analysis of systematic review. 
this can lead to selection bias. On the positive aspects, the paper clearly defines the research question. This is important, as we know a well-defined research question is key to developing a methodology. The research question should address all aspects of the study and should be as specific as possible. The study design is clear and well described. The paper analyses statistics well, using the appropriate tests for the data such as using a paired t test for comparing samples, unpaired t test for comparing parametric data and MannWhitney U test for non-parametric tests.

Steffen et al reported the effect of blood flow on the femoral head during different steps of surgery in 10 patients during hip resurfacing, using oxygen concentration as a surrogate to blood flow and using posterior approach as the surgical method of choice [9]. All patients had a posterior approach and the measurements were taken at different stages of the operation. In this study they demonstrated that the biggest drop occurs at the time the MCFA artery is cut $(\mathrm{p}<0.005)$. The paper analyses the results effectively using appropriate statistical tests.

In the article published in the journal "Hip International", Khan et al [2] reported a two-year follow up study of outcome following antero-lateral approach compared to a trochanteric flip approach. The research question is not clearly stated at the outset. The authors have compared two surgical approaches, the trochanteric flip and the antero-lateral approach. A total of 46 (24 trochanteric flip and 22 in anterolateral group) have been included. They have not been selected consecutively nor have they been randomly allocated to one group. The patient details including the demographics are not mentioned and therefore we do not know whether the two groups were comparable. However on the positive aspect the methodology section describes the operative protocol, post-operative rehabilitation and follow-up details, which is equally distributed in both groups. Outcome measures included an Xray at six to eight weeks and Harris and Oxford hip scores at one year and yearly intervals thereafter. The outcome measures lack clarity. However, the paper highlights the limitation of the trochanteric flip approach and suggests an alternative approach to address this issue while preserving the femoral head blood flow.

Schoeniger et al [3] studied the extra-osseous blood supply in osteoarthritic femoral heads by comparing metaphyseal and epiphyseal blood flow before and after compression of retinacular vessels. Then, the epiphyseal flow was further studied at different stages of surgery; after capsulotomy, osteotomy and transection. As described previously this too has small numbers $(\mathrm{n}=10)$ and a non-randomised design along with a lack of a clear comparison group. However the strengths of the paper are the clear research question and description of methodology, including the measurement protocol of blood flow. Statistical analysis is well represented using error bars showing standard error of mean in the graph.
It is important to show error bars and $p$ values in a bar chart to identify a statistical significant difference between the compared data sets.

Steffen et al reports in the article titled " femoral oxygenation during hip resurfacing arthroplasty through the trochanteric flip approach", that antero-lateral and trochanteric flip approaches preserve similar oxygen levels while oxygenation in the posterior approach show a significant reduction [4]. This studied a total of 15 patients and a sample size calculation has not been done. All patients underwent the trochanteric flip approach. Patients have not been recruited in a consecutive manner, which can lead to selection bias. The comparison groups are from a previous study. Unless these are matched or results analysed accordingly this becomes a potential limitation. The strength of the paper appears to be the detailed description of measurement protocol that has not been violated in any one measurement. The protocol violation during data collection may be a limitation of the study.

This paper has similar characteristic to the previously described paper [4] such as a small sample size without a power calculation, a non-randomised design and the comparison group taken from a previous study without a clear matching of the two groups. The key positive aspects of the paper include the detailed description of the protocol of measurement and the well-presented statistical analysis of results.

In the article titled "Femoral head blood flow during hip resurfacing", Beaule et al [8] showed that during the reaming process the femoral head blood flow can reduce by $70 \%$. The total number studied was 10 , but they were consecutively selected as compared to previous studies. The number of patients is small and limited to 10 hips. Even though the study is clinically relevant, the research question was not clearly formulated and there is no clear comparison group. The positive aspect includes the clear statistical analysis and mentioning the limitations of the study in the discussion. The small number, lack of randomisation, poorly formed research question and lack of comparison group all remain limitations of the study.

Sugamoto et al [11] compared blood flow to the femoral head in 28 femoral neck fractures and 16 inter trochanteric fractures with 14 patients with osteoarthritis using LASER Doppler flowmetry. In this paper the research question is not clearly defined. It appears to be like a large case series. A positive aspect of the paper is the publication of raw data. In the discussion, authors have over emphasised the results and interpreted beyond the data it represents. As an example the authors say "only LASER Doppler is useful in evaluation of hemodynamic impediments and selecting a proper treatment method". This conclusion cannot be drawn from this study nor have they given a reference to support this statement. 
A Retrieval analysis done by Steffen et al [12] studied the vascularity of femoral head after hip resurfacing. They used the method of counting percentage of empty lacunae as an indication of avascular necrosis. The research question is clearly defined. The study is a comparison between the failure caused by a femoral neck fracture and other causes in hip resurfacing. Even though a formal sample size calculation is not mentioned the total number of specimens studied were 55 . In the methodology section the study is well described on the basis of PICO (Patients, Intervention, comparison group, and outcome measures). The authors have also used a new method to assess the vascularity by counting the percentage of empty lacunae in the histology specimens. Whenever a new method is used or introduced in a research project it should be validated by a comparison study with an established method or by assessing the reproducibility of the method. It is also important to assess the intra- and inter-observer variability by performing an agreement study. As the authors have done this, this method of nuclear counting could be considered as a validated method.

Beaule et al [15] published an article titled "vascularity of the arthritic femoral head and hip resurfacing" that involved a cadaveric dissection of specimens to study the arterial pattern. This is essentially a descriptive study as compared to most research studies that are analytical [17]. The authors describe dissection of 174 cadaveric specimens to identify the anatomical pattern of the femoral head blood flow, mainly the anatomy of the medial circumflex femoral artery (MCFA) and its branches. This study describes a detail anatomical pathway of the blood supply of the adult arthritic hip. Firstly the number of hips remains low as a percentage of the total representative population of adult osteoarthritis. This means variations and the uniformity of distribution of this anatomy cannot be calculated as it will require a power calculation. However the methodology is systematic and well described and can be reproduced in a larger study. In that context, this study can act as a pilot study. The second negative point is that the paper lacks a clear structure in representing the results.

\section{Conclusions}

This systematic review was able to retrieve articles that were published on the effect of the blood flow to the femoral head during different surgical approaches. There are few limitations to the study. Firstly, the search period was limited to 1990 and 2014, articles published prior to this was not included. The main reason for the clinical significance of the question lies within the period that hip resurfacing was reintroduced. Secondly all searches were done using online databases. Thirdly only articles published in the english language was included. Even though they were mentioned as exclusion criteria, all these act as limitations. Some articles compared blood flow during different surgical approaches whilst others compared the blood flow during different stages of a single approach. We also noticed a lack of cadaveric and retrieval studies within the search that could be done to assess the permanent impact to the vascularity of the femoral head.

When critically appraising the final set of articles it was obvious that there were no randomised control trials on this topic. We strongly believe that this is an area that needs further research and a randomised control trial (RCT) to be conducted. However, there is a fine balance between the cost and the clinical significance of the research topic as conducting an RCT is very costly. Over many decades we have been able to demonstrate that the posterior approach reduces blood flow to the femoral head compared to other approaches. However, we are still unable to clearly show whether this reduction leads to the development of AVN. At the moment evidence seems to be against this than for it $[18,19]$.

The author discloses no conflict of interest. The study was conducted in accordance with the ethical standards of the relevant institutional or national ethics committee and the Helsinki Declaration of 1975, as revised in 2000 .

\section{References}

1. Tucker FR. Arterial supply to the femoral head and its clinical importance. The Journal of bone and joint surgery British volume 1949; 31B: 82-93.

2. Khan RM, Cooper G, Hull JB. Hip resurfacing through a modified anterolateral approach, as compared with the Ganz trochanteric flip osteotomy: a two year follow-up study. Hip international : the journal of clinical and experimental research on hip pathology and therapy 2009; 19: 338-42.

3. Schoeniger R, Espinosa N, Sierra RJ, Leunig M, Ganz R. Role of the Extraosseus Blood Supply in Osteoarthritic Femoral Heads? Clinical orthopaedics and related research 2009. http://dx.doi.org/10.1007/s11999-009-0839-1

4. Steffen RT, Fern D, Norton M, Murray DW, Gill HS. Femoral Oxygenation During Hip Resurfacing Through the Trochanteric Flip Approach. Clinical orthopaedics and related research 2008.

5. Amarasekera HW1, Costa ML, Foguet P, Krikler SJ, Prakash U, Griffin DR. The blood flow to the femoral head/neck junction during resurfacing arthroplasty: a comparison of two approaches using Laser Doppler flowmetry. J Bone Joint Surg Br. 2008 Apr; 90(4): 442-5. doi: 10.1302/0301-620X.90B4.20050.

6. Steffen R, O'Rourke K, Gill HS, Murray DW. The anterolateral approach leads to less disruption of the femoral head-neck blood supply than the posterior approach during hip resurfacing. The Journal of bone and joint surgery British volume 2007; 89: 12938. http://dx.doi.org/10.1302/0301-620X.89B10.18974

7. Khan A, Yates P, Lovering A, Bannister GC, Spencer RF. The effect of surgical approach on blood flow to the femoral head during resurfacing. The Journal of bone and joint surgery British volume 2007; 89:21-5. http://dx.doi.org/10.1302/0301-620X.89B1.18330

8. Beaule PE, Campbell P, Shim P. Femoral head blood flow during hip resurfacing. Clinical orthopaedics and related research 2007; 
456: $148-52$

http://dx.doi.org/10.1097/01.blo.0000238865.77109.af

9. Steffen RT, Smith SR, Urban JP, et al. The effect of hip resurfacing on oxygen concentration in the femoral head. The Journal of bone and joint surgery British volume 2005; 87: 1468-74.

http://dx.doi.org/10.1302/0301-620X.87B11.16780

10. ElMaraghy AW, Schemitsch EH, Waddell JP. Greater trochanteric blood flow during total hip arthroplasty using a posterior approach. Clinical orthopaedics and related research 1999: 151-7.

http://dx.doi.org/10.1097/00003086-199906000-00019

11. Sugamoto K, Ochi T, Takahashi Y, Tamura T, Matsuoka T. Hemodynamic measurement in the femoral head using laser Doppler. Clinical orthopaedics and related research 1998: 13847. http://dx.doi.org/10.1097/00003086-199808000-00016

12. Steffen RT, Athanasou NA, Gill HS, Murray DW. Avascular necrosis associated with fracture of the femoral neck after hip resurfacing: histological assessment of femoral bone from retrieval specimens. The Journal of bone and joint surgery British volume 2010; 92: 787-93. http://dx.doi.org/10.1302/0301-620X.92B6.23377

13. Shimmin AJ, Walter WL, Esposito C. The influence of the size of the component on the outcome of resurfacing arthroplasty of the hip: a review of the literature. The Journal of bone and joint surgery British volume 2010; 92: 469-76.

http://dx.doi.org/10.1302/0301-620X.92B4.22967

14. Sandri A, Regis D, Magnan B, Luminari E, Bartolozzi P. Hip resurfacing using the anterolateral Watson-Jones approach in the supine position. Orthopedics 2009; 32: 406. http://dx.doi.org/10.3928/01477447-20090511-09

15. Beaule PE, Campbell P, Lu Z, et al. Vascularity of the arthritic femoral head and hip resurfacing. The Journal of bone and joint surgery American volume 2006; 88 Suppl 4: 85-96. http://dx.doi.org/10.2106/JBJS.F.00592

16. Rockwood JH WD, Sekiya JK. Arthroscopic management of avascular necrosis. Operative Techniques in Orthopaedics 2005; vol./is. 15/3(273-279), 10486666.

17. Woodward M. Epidemiology:Study design and data analysis. 2nd Edition ed. Florida,USA Boca Raton,FL : Chapman and Hall; 2004.

18. Khan A, Lovering AM, Bannister GC, Spencer RF, Kalap N. The effect of a modified posterior approach on blood flow to the femoral head during hip resurfacing. Hip international : the journal of clinical and experimental research on hip pathology and therapy 2009; 19: 52-7.

19. Amarasekera HW, Campbell PC, Parsons N, et al. The effect of surgical approach on the histologyof the femoral head following resurfacing of the hip: Analysis of retrieval specimens. Bone \& joint research 2013; 2: 200-5. http://dx.doi.org/10.1302/2046-3758.29.2000179 